\title{
A ATUAÇÃO DO PROJETO GRUPO DE APOIO EM MATEMÁTICA NO PERÍODO 2010-2020: PRINCIPAIS AÇÕES E RESULTADOS
}

\author{
THE PERFORMANCE OF THE MATHEMATICS SUPPORT GROUP PROJECT IN THE \\ PERIOD 2010-2020: MAIN ACTIONS AND RESULTS
}

\author{
Rejane Pergher ${ }^{\mathrm{T}}$ \\ Cícero Nachtigall ${ }^{2}$
}

RESUMO: É inegável que as universidades federais brasileiras passaram, nas últimas duas décadas, por um período de profundas transformações. Por meio da implementação do Plano de Reestruturação e Expansão das Universidades Federais, foram realizados significativos investimentos, visando ampliar o acesso e a permanência dos estudantes nas Instituições de Ensino Superior Federais. A criação de novos cursos e a abertura de novas vagas convidaram essas instituições a implementar novas ações, visando oferecer apoio aos estudantes ingressantes. $\mathrm{Na}$ Universidade Federal de Pelotas, um grupo de professores criou, em 2010, o Projeto GAMA: Grupo de Apoio em Matemática, com o objetivo inicial de suprir carências de aprendizagem matemática oriundas dos níveis fundamental e médio, bem como auxiliar a aprendizagem matemática dos estudantes ao longo da graduação. Esta pesquisa tem o objetivo de apresentar e analisar as principais frentes de atuação e os principais resultados obtidos no período de 2010 a 2020. A coleta de dados teve como fonte os relatórios anuais e publicações na página institucional do grupo. Trata-se, portanto, de uma pesquisa documental e longitudinal. Os resultados apontaram que neste período houve uma significativa diversificação na quantidade e na natureza das atividades desenvolvidas. Através de atividades de ensino, pesquisa e extensão, o GAMA implementou novas ações e agregou novas metodologias de ensino, promovendo a cultura do "aprender a aprender". Ao proporcionar apoio em matemática a cerca de 500 alunos por semestre, em média, o grupo vem se destacando pela sua atuação na linha de frente no combate à evasão e retenção e é considerado, atualmente, um projeto estratégico institucional.

Palavras-chave: Permanência acadêmica. Ensino e aprendizagem. Cálculo Diferencial e Integral.

\footnotetext{
I Possui Graduação em Matemática Aplicada e Computacional pela Universidade Federal do Rio Grande do Sul (1995). Mestrado em Matemática Aplicada pela Universidade Federal do Rio Grande do Sul (1997). Doutorado em Engenharia Mecânica pela Universidade Federal do Rio Grande do Sul (2003). Atualmente é professora associada da Universidade Federal de Pelotas. Coordenadora do projeto GAMA desde 2021. Email: rejane.pergher@gmail.com.

${ }^{2}$ Possui Graduação em Curso de Licenciatura Plena em Matemática pela Universidade Federal de Pelotas (2003), Mestrado em Matemática pela Universidade Federal do Rio Grande do Sul (2006) e mestrado em Educação Matemática pela Universidade Federal de Pelotas (2020), Doutorado em Matemática na Universidade Estadual de Campinas (20II). Atualmente, é professor associado da Universidade Federal de Pelotas e cursa Doutorado em Educação nesta instituição. Coordenou o curso de Licenciatura em Matemática - Noturno no período de 2014 a 2016 e o projeto GAMA: Grupo de Apoio em Matemática no período de 2015 a 2021. E-mail: ccnachtigall@yahoo.com.br.
} 
ABSTRACT: It is undeniable that the Brazilian federal universities have, in the last two decades, gone through a period of profound transformations. Through the implementation of the Federal Universities Restructuring and Expansion Plan, significant investments were made, aiming at expanding students' access and permanence in Federal Higher Education Institutions. The creation of new courses and the opening of new vacancies invited these institutions to implement new actions, aiming to offer support to incoming students. At the Federal University of Pelotas, a group of teachers created, in 2010, the GAMA Project: Support Group in Mathematics, with the initial objective of supplying deficiencies in mathematical learning from the elementary and high school levels, as well as helping students' mathematical learning throughout graduation. This research aims to present and analyze the main fronts of action and the main results obtained in the period from 2010 to 2020. The data collection was based on the annual reports and publications on the group's institutional page. It is, therefore, a documentary and longitudinal research. The results showed that in this period there was a significant diversification in the quantity and nature of the activities developed. Through teaching, research and extension activities, GAMA implemented new actions and added new teaching methodologies, promoting the culture of "learning to learn". By providing support in mathematics to about 500 students per semester, on average, the group has been standing out for its role in the front line in combating evasion and retention and is currently considered an institutional strategic project.

Keywords: Academic permanence. Teaching and learning. Differential and integral calculus.

\section{INTRODUÇÃO}

Ao longo das últimas duas décadas, as Universidades Federais passaram por profundas e significativas transformações. Os investimentos realizados no período de 2007 a 2012, por intermédio do Plano de Reestruturação e Expansão das Universidades Federais - REUNI (BRASIL, 2007a, 2007b), permitiram um significativo acréscimo na quantidade de cursos de graduação e, consequentemente, a ampliação do número de estudantes em diversas universidades federais brasileiras. Em particular, muitos cursos nas áreas de exatas e engenharias, que exigem uma formação sólida em matemática, foram implementados. Se, por um lado, esta expansão trouxe a democratização do acesso ao ensino superior, por outro, o aumento na oferta de cursos implicou na necessidade de implementação de novas ações, visando oferecer apoio aos estudantes ingressantes, especialmente na área de matemática.

Como destaca Almeida (2006), são muitas as dificuldades e os problemas relacionados à educação matemática, tanto no ensino e aprendizagem, quanto na formação de professores,

[...] o tema dificuldade no aprendizado em Matemática tem sido objeto de pesquisas, palestras, encontros, com o objetivo de descobrir as origens de tantos problemas no ensino. Algumas questões são recorrentes nestes debates e pesquisas, tais como: A deficiência está no próprio sistema de ensino? Os professores não estão conseguindo lidar com o processo? Os alunos não estariam desmotivados? $\mathrm{O}$ que leva o aluno a não conseguir aprender Matemática e/ou outras disciplinas? Além dessas, muitas outras questões vêm sendo levantadas a 
fim de buscar uma resposta e possíveis soluções para os problemas enfrentados atualmente na educação. (Almeida, 2006, p.2).

Nesta perspectiva, o PISA $^{3}$ (Programa Internacional de Avaliação dos Estudantes), considerado um dos maiores indicadores educacionais mundiais, aponta uma considerável defasagem na aprendizagem matemática básica dos estudantes brasileiros. Esse levantamento indica que pelo menos 40\% dos I0.96r alunos brasileiros participantes na edição realizada em 2018 se encontram abaixo do nível considerado básico para o exercício pleno da cidadania, sendo incapazes de resolver questões matemáticas consideradas simples e rotineiras. Segundo esse levantamento, apenas $0,1 \%$ dos alunos brasileiros participantes apresentou nível máximo de proficiência na área de matemática. A defasagem é mais significativa entre estudantes da rede pública de ensino. Nesta perspectiva, iniciativas que visam acolher os estudantes ingressantes se tornam ainda mais significativas a partir da promulgação da lei 12.711/2012, de 29 de agosto de 2012, regulamentada pelo Decreto $\mathrm{n}^{\mathrm{o}} 7.824 / 2012$, que dispôs sobre o ingresso nas universidades federais, estabelecendo que $50 \%$ das vagas de ingresso deveriam ser preenchidas por alunos oriundos integralmente do ensino médio público, em cursos regulares ou da educação de jovens e adultos (EJA).

$\mathrm{Na}$ UFPel, um grupo de professores criou em 2010 o projeto Tópicos de Matemática Elementar: Matemática Básica - Iniciação ao Cálculo, que foi renomeado em 2015 e passou a se chamar projeto GAMA: Grupo de Apoio em Matemática. Desde a sua criação, este projeto se dedica a pensar, propor e executar diversas ações de acolhida à estudantes que procuram apoio institucional para revisão e reforço em matemática, tanto em nível elementar (conteúdos de ensino fundamental e médio) quanto em nível de graduação (conteúdos de ensino superior).

Como destaca Cabral (2015, p. 210), a transição do ensino médio para o universitário exige mudanças na própria maneira de pensar e "pode-se dizer que se trata de uma quebra de paradigmas, impactando o modo como o aluno lida com o conhecimento, exigindo-lhe uma modificação na sua atitude; o que comumente não acontece".

Dentre as dificuldades mais frequentes na aprendizagem de cálculo, Flores (2018) destaca os conheciementos prévios dos estudantes, e destaca que:

\begin{abstract}
A monitoria é uma alternativa para a superação dessas fragilidades, sem ocupar o tempo da aula regular ou gerar custos extras. No entanto, para que isso seja possível, é necessário que o monitor conheça as lacunas conceituais apresentadas pelos discentes, a fim de traçar uma ação direcionada a tornar os a-encontrar em já-encontrados. (FLORES, 2018, p. 213)
\end{abstract}

\footnotetext{
${ }^{3}$ http://www.oecd.org/pisa/
} 
Ao longo de quase uma década, desde a sua criação, o GAMA se tornou um projeto tradicional da UFPel, com atuação reconhecida através de seu compromisso para com a comunidade acadêmica e passou a ser classificado, a partir de 2018, como projeto estratégico institucional. Atualmente, o GAMA vem se dedicando especialmente a buscar alternativas para vencer um dos principais desafios característicos do ensino tradicional: a passividade dos alunos em relação a sua própria aprendizagem. Esta particularidade, facilmente identificada em muitas salas de aula, dificulta e até mesmo impossibilita uma aprendizagem de qualidade.

Dada a consistente trajetória do grupo, este artigo tenta responder a seguinte pergunta de pesquisa: Quais as principais ações que foram desenvolvidas e quais resultados podem ser identificados por meio da atuação do GAMA no período de 2010 a 2020?

\section{METODOLOGiA}

Esta pesquisa apresenta um desenho longitudinal de tendência. Segundo Sampieri, Collado e Lucio (2013, p. 177), estas pesquisas visam "analisar mudanças que ocorreram ao longo do tempo em determinadas categorias, conceitos, eventos, variáveis, contextos ou comunidades, ou, ainda, entre suas relações."

Quanto aos procedimentos, esta investigação é classificada como uma pesquisa documental. Segundo Cervo, Bervian e Silva (2007, p. 62), nas pesquisas documentais "são investigados documentos com o propósito de descrever e comparar os usos e costumes, tendências, diferenças e outras características".

Para Gil (2018, p. 5I), as fontes da pesquisa documental são "materiais que não receberam ainda o tratamento de pesquisa analítico, ou que ainda podem ser reelaborados de acordo com os objetivos da pesquisa". Nesta mesma perspectiva, o autor destaca que as fontes podem ser classificadas em dois grupos distintos, sendo o primeiro composto por documentos que ainda não receberam qualquer tratamento analítico e, o segundo, composto por documentos que, de alguma forma, já foram analisados, como é o caso de relatórios (GIL, 2018).

As fontes de dados desta pesquisa foram os relatórios anuais do projeto Tópicos de Matemática Elementar: Matemática Básica - Iniciação ao Cálculo (de 2010 a 2014), relatórios do Grupo de Apoio em Matemática (de 2015 a 2020), consultas à página institucional do GAMA4, à página do grupo na rede social facebook e ao canal de videoaulas no YouTube ${ }^{6}$.

\footnotetext{
${ }^{4}$ https://wp.ufpel.edu.br/projetogama/

$s$ https://www.facebook.com/projetogamaufpel
} 


\section{RESULTADOS E DISCUSSÕES}

Os dados documentais coletados possibilitaram traçar um panorama de atuação do grupo no período de 2010 a 2020. As apresentações dos resultados foram agrupadas em três momentos distintos:

I) $\mathrm{O}$ nascimento e os primeiros passos: $\mathrm{O}$ projeto TME;

2) Novos desafios: A criação e a implementação das Atividades de Reforço em Cálculo;

3) Novos horizontes: A implementação de ações baseadas em outras perspectivas teóricas e metodológicas.

\section{O nascimento e os primeiros passos: $\mathrm{O}$ projeto TME}

Nessa seção, encontram-se organizados os registros de criação e implementação das primeiras ações do grupo, abrangendo o período cronológico que foi desde a sua criação, em 2010, até o ano de 2014 .

O projeto foi idealizado por um grupo de professores do Departamento de Matemática e Estatística, do Instituto de Física e Matemática da UFPel, todos recém integrados ao quadro docente da instituição. O GAMA foi intitulado, inicialmente, de Projeto Tópicos de Matemática Elementar: Matemática Básica - Iniciação ao Cálculo (TME) e só passou a ser denominado Grupo de Apoio em Matemática a partir de 2015. Nestes primeiros anos, o grupo oferecia monitorias durante os semestres letivos e um curso de matemática básica para alunos ingressantes nos recessos acadêmicos. As monitorias, neste período, eram desenvolvidas de maneira personalizada, com atuação individual de um bolsista por turma (CABRERA et al., 2013). Neste modelo, cabia ao professor responsável pela turma solicitar o apoio do projeto. O curso de matemática básica era composto por seis aulas, ministradas por bolsistas e acompanhadas presencialmente por professores colaboradores do grupo. O objetivo deste curso era de sanar algumas lacunas na aprendizagem de conceitos fundamentais para as disciplinas iniciais de cálculo diferencial e integral.

Apresentamos, na tabela a seguir, um resumo do trabalho desenvolvido pelo grupo, nos quatro primeiros anos, onde a monitoria e o curso de matemática básica eram as principais ações.

\begin{tabular}{|c|c|c|c|c|c|}
\hline Ano & 2011 & 2012 & 2013 & 2014 & Total \\
\hline Número de alunos atendidos & 789 & 671 & 779 & 648 & 2.887 \\
\hline
\end{tabular}

\footnotetext{
${ }^{6}$ https://www.youtube.com/channel/UCB3NNUeew6Ji_k39-_GDA3iQ
} 
Tabela I: Estudantes apoiados pelo projeto GAMA no período de 2011 a 2014

\section{Novos desafios: A criação e a implementação das Atividades de Reforço em Cálculo}

A partir de 2015, atendendo a um pedido da Pró-Reitoria de Assuntos Estudantis PRAE/UFPel que visava potencializar o apoio a estudantes em situação de vulnerabilidade social, através de aulas de reforço em matemática elementar, o GAMA desenvolve e implementa as Atividades de Reforço em Cálculo (ARC). Nesta proposta, cada turma realizava um encontro semanal de quatro horas onde eram revisados conteúdos de matemática elementar e Cálculo Diferencial. A proposta visou desenvolver o conteúdo de forma paralela ao desenvolvido na disciplina de Cálculo na qual o aluno estava matriculado. Ao contrário das monitorias, onde geralmente são discutidas dúvidas específicas, estas atividades propõem a revisão sistemática da teoria e, em seguida, resolução de exemplos e exercícios pré-estabelecidos.

A partir de 2017, as Atividades de Reforço em Cálculo passaram a representar a principal ação oferecida pelo grupo, em número de estudantes participantes. Estruturadas em módulos de revisão tanto do ensino básico quanto superior. Cada módulo é composto por seis aulas presenciais envolvendo conteúdo e exercícios. Das vagas oferecidas, 50\% são destinadas para alunos vinculados a programas de permanência da Pró-reitoria de Assuntos Estudantis. Cada turma tem aula duas vezes por semana, com duração de duas horas cada encontro ou uma única vez por semana, em um encontro de quatro horas oferecido geralmente aos sábados pela manhã.

Os módulos de reforço oferecidos atualmente são: Matemática Básica I, Matemática Básica II, Funções, Funções trigonométricas, exponenciais e logarítmicas, Limites, Derivadas e Integrais. As inscrições e a divulgação das turmas é realizada na página institucional do GAMA. O participante que obtiver presença em 75\% das aulas recebe certificado de 12 horas em cada módulo.

Além das Atividades de Reforço em Cálculo, o GAMA mantém o atendimento dos estudantes através de monitorias, que são oferecidas ao longo dos semestres letivos. Os bolsistas disponibilizam I2 horas semanais em três campi da universidade, com horários nos três turnos e, neste formato, as monitorias deixaram de ser personalizadas por turma, o que possibilitou a participação de um maior número de estudantes. $\mathrm{Na}$ página institucional do grupo é disponibilizada uma tabela com todos os horários disponíveis, nomes dos monitores, disciplinas atendidas e locais, atualizada sempre que necessário. Os alunos que comparecem a is monitorias recebem um certificado de 20 horas.

A cada semestre, um levantamento sobre aprovação, reprovação e infrequência nas disciplinas de Cálculo dos estudantes que procuram atendimento é realizado e divulgado na página 
do GAMA. A tabela 2 mostra a quantidade de alunos atendidos pelo GAMA de 2015 a 2017, nas diversas atividades oferecidas pelo projeto.

\begin{tabular}{|c|c|c|c|c|}
\hline Ano & 2015 & 2016 & 2017 & Total \\
\hline Número de alunos atendidos & 703 & 968 & 1012 & 2.683 \\
\hline
\end{tabular}

Tabela 2: Estudantes apoiados pelo projeto GAMA no período de 2015 a 2017

Ao comparar a quantidade de estudantes participantes do projeto no período 2011-2014 (Tabela I), é possível perceber que houve um aumento na quantidade de estudantes participantes no período 2015-2017 (Tabela 2). Acredita-se que este aumento tenha sido ocasionado pela diversificação nas atividades do grupo, proporcionadas pelas Atividades de Reforço em Cálculo.

Uma particularidade encontrada na página do grupo é um espaço destinado a depoimentos7. Criado no final do ano de 2017, este recurso possibilita aos participantes do projeto o registro de manifestações voluntárias acerca de suas experiências no GAMA. Atualmente, a página conta com mais de quarenta depoimentos de estudantes participantes, ex-bolsistas e servidores da universidade. Em geral, os depoentes exaltam a importância do projeto enquanto iniciativa qualificadora da aprendizagem matemática na UFPel.

\section{Um novo horizonte: A implementação de ações baseadas em novas perspectivas teóricas e metodológicas}

Em 2018, iniciou-se a postagem de videoaulas no canal do grupo no YouTube ${ }^{8}$. Inicialmente, havia 31 videoaulas que abordavam integralmente os conteúdos do módulo de matemática básica. Os vídeos foram gravados por um bolsista e editados por um professor do grupo. Nos anos de 2018 e 2019, o canal começou a ser acessado, alcançou mais de 200 inscritos e ultrapassou seis mil visualizações. Os vídeos foram gravados utilizando a webcam do computador, um gravador para captação de áudio, o software OBS Studio para captação dos movimentos da tela e o software OpenShot para edição de vídeos.

Cada vídeo é composto por uma apresentação do conteúdo, em slides de powerpoint, acopladas à imagem do apresentador, em tamanho reduzido, narrando a explicação no canto inferior esquerdo da tela, como mostra a Figura I. Optou-se por mesclar os slides de conteúdo com a imagem do bolsista e não somente o recurso de áudio, na apresentação da aula, por entender-se que a imagem do bolsista poderia representar um recurso importante para aproximar o estudante da aula, qualificando assim a aprendizagem.

\footnotetext{
7 https://wp.ufpel.edu.br/projetogama/depoimentos/

${ }^{8}$ https://www.youtube.com/channel/UCB3NUeew6Ji_k39-GDA3iQ
} 


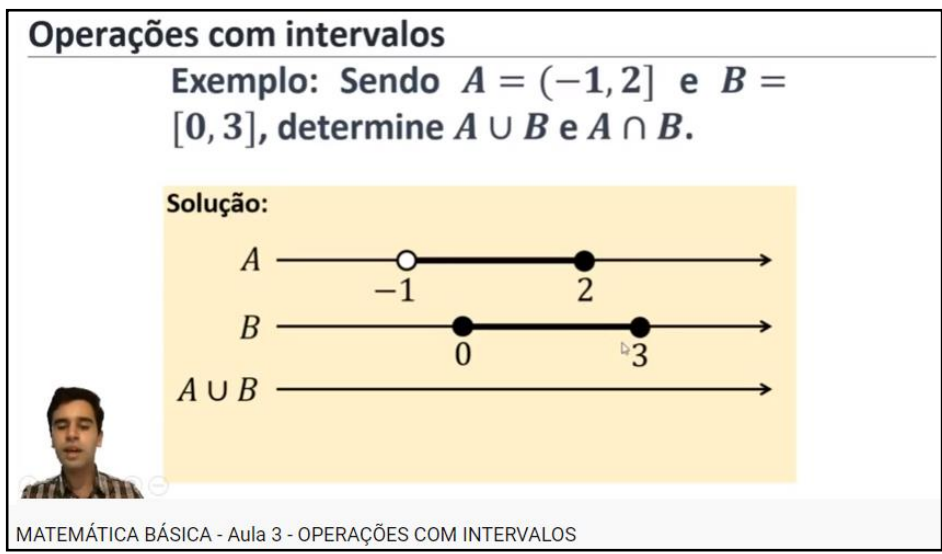

Figura r: Formato das videoaulas

Também em 2018, surgiu a ideia de criar um grupo de whatsapp entre alunos, bolsistas e professores, a fim de ser mais um canal de auxílio em dúvidas de matemática em horários que porventura não tenha monitoria ou não seja possível o deslocamento até a universidade. Esta iniciativa tem se mostrado muito eficiente, especialmente em períodos nos quais os atendimentos presenciais não são possíveis. Como observa Flores (2018, p. 49), a tecnologia digital "colabora para equacionar problemas de aprendizagem e, ao mesmo tempo, provoca um trabalho coletivo entre todas as partes envolvidas. Essa perspectiva indica a monitoria como uma ação planejada, pressupondo comunicação e interação entre as partes".

A parir de 2019, o GAMA deixa de ser um projeto de ensino da UFPel e passa a ser cadastrado em uma nova modalidade, como "projeto unificado". Nesta nova modalidade, passa a ser permitida a oferta de ações de pesquisa e extensão, além das tradicionais atividades de ensino já desenvolvidas pelo grupo desde a sua criação. Estudantes e professores da rede pública de ensino passam a participar das atividades do grupo e isto fomenta uma aproximação do GAMA com instituições de educação básica.

Também neste ano, uma nova metodologia de ensino foi utilizada no módulo de matemática básica, chamada Sala de Aula Invertida - SAI, a fim de obter um aprendizado mais significativo. Nesta proposta, vídeos pedagógicos produzidos pelo grupo foram enviados previamente para os estudantes da turma antes de cada aula presencial. Os estudantes assistiram os vídeos e compareceram no encontro presencial para esclarecer dúvidas e resolver exercícios. Nesta proposta, o que seria feito em aula (primeira exposição do conteúdo) agora é feito em casa e o que era feito em casa (resolver os exercícios) é feito em aula, com o auxílio de colegas, monitores e professores. Por inverter os elementos típicos da sala de aula tradicional, esta abordagem recebe o 
nome de flipped classroom - sala de aula invertida (BERGMANN, 2or8; BERGMANN e SAMS, 2018; TALBERT, 2019). A SAI configura, assim, uma abordagem híbrida, mesclando elementos típicos do ensino presencial e online (BACICH, NETO e TREVISANI, 2015; HORN e STAKER, 2015) que propõe uma postura ativa do estudante em relação a sua aprendizagem (BACICH e MORAN, 2018; MATTAR, 2017). A primeira experiência de implementação da SAI no GAMA indicou maior personalização do ensino, autonomia do discente, interação professor/aluno e aluno/aluno e melhora na aprendizagem, de acordo com a percepção dos participantes da pesquisa (NACHTIGALL, 2020).

Como destaca Flores (2018),

É clara a urgência de ações que levem a melhores índices de aprovação, mas sobretudo à construção do conhecimento matemático, visualizando o Cálculo com uma possibilidade de leitura e interpretação do mundo. A monitoria apresenta um potencial para promover a aprendizagem e reverter o cenário observado. No entanto, pode haver aí uma armadilha: quando desacompanhada de um olhar pedagógico, ela pode servir apenas de espaço para a reprodução de um modelo educacional já existente, que se fundamenta na transmissão de informações e produz poucos impactos em relação à construção do conhecimento. (FLORES, 2018, p. 21I)

No ano de 2020, já no contexto de isolamento social causado pela pandemia da COVID-ı, o grupo mais uma vez se reinventa, agregando duas novas ações. A primeira delas, diretamente relacionada à impossibilidade de atividades presenciais, consistiu em gravar mais de 150 vídeos pedagógicos que abrangem o conteúdo dos módulos de Funções (I4 vídeos), Funções Trigonométricas, Exponenciais e Logarítmicas (20 vídeos), Limites (13 vídeos), Derivadas (I2 vídeos), Integrais (2I vídeos), Álgebra Linear e Geometria Analítica (27 vídeos), além de diversos vídeos que versam sobre resoluções de exercícios. As videoaulas foram baseadas no material didático desenvolvido para as aulas presenciais do GAMA e foram produzidas por professores do grupo. A confecção deste material permitiu oferecer diversas atividades online ao longo de $2020 \mathrm{e}$ 2021, tanto para estudantes da UFPel quanto para estudantes de outras instituições públicas de ensino, reforçando o caráter extensionista.

A segunda ação agregada ao GAMA a partir do ano de 2020 foram as Oficinas de Aprendizagem Autorregulada. Panadero e Alonso-Tapia (2014, p. 451) definem a autorregulação como "o controle que o sujeito realiza sobre seus pensamentos, ações, emoções e motivação através de estratégias pessoais para alcançar objetivos estabelecidos". Zimmerman (1989), enfatiza que a autorregulação da aprendizagem abrange aspectos metacognitivos, motivacionais e comportamentais. $\mathrm{O}$ autor destaca que a aprendizagem autorregulada permite ao estudante iniciar 
e direcionar seus próprios esforços para adquirir conhecimento e habilidade. Zimmermann (200o) aponta três fases distintas na autorregulação: antecipação, execução ou controle volitivo e autorreflexão. Estas fases compõe um modelo cíclico.

A fase de antecipação refere-se ao processo de influencias e crenças que precedem os esforços para aprender e estabelecem o cenário para essa aprendizagem. A segunda fase de autorregulação, execução ou controle volitivo, envolve processos que ocorrem durante os esforços de aprendizagem e afetam a concentração e a execução. A terceira fase autorregulatória, autorreflexão, envolve processos que ocorrem após os esforços de aprendizagem e influenciam as reações dos alunos para aquela experiência. A autorreflexão, por sua vez, influencia a antecipação em relação aos esforços de aprendizagem subsequentes, completando assim o ciclo autorregulatório (ZIMMERMAN, 200o, p. 16).

Os alunos autorregulados caracterizam-se por serem decididos, persistentes e estratégicos. Eles monitoram o seu desempenho e realizam ajustes constantes em seu comportamento para alcançarem suas metas. Além da postura ativa do aluno, o contexto de aprendizagem é determinante para o desenvolvimento da autorregulação da aprendizagem. O professor, nesta perspectiva, desempenha um papel estratégico pela possibilidade de proporcionar, sistematicamente, circunstâncias favoráveis para o desenvolvimento de estratégias de autorregulação da aprendizagem em seus alunos (ROSÁRIO, 200I).

Nesta perspectiva, Simão e Frison (2013) acrescentam que,

[...] o processo começa com a definição de metas e de objetivos que o indivíduo pretende alcançar, continua com a preparação de um planejamento, onde expectativas, crenças, cognições e motivações representam um papel importante. Segue-se a execução de ações planejadas em interação com o meio, onde motivações e volições se transformam em incentivos que ajudam a manter a persistência e a direção do comportamento e, finalmente, avalia os resultados e compara-os com os pretendidos, onde sentimentos de satisfação ou de fracasso poderão interferir no caminho traçado. (SIMÃO e FRISON, zor3, p. 6)

É imprescindível que as instituições de ensino promovam estratégias autorregulatórias nos estudantes, visando proporcionar melhores condições de progresso na aprendizagem tanto em relação aos conteúdos que o aluno está aprendendo, no estágio atual no qual se encontra, quanto em relação às próximas aprendizagens. Muito além de aprender um conteúdo específico, trata-se de oportunizar que os alunos possam efetivamente aprender a aprender (ROSÁRIO, 200I).

O oferecimento da primeira turma ocorreu ao longo do mês de novembro de 2020. Esta atividade foi composta por quatro encontros virtuais síncronos, além de atividades assíncronas, onde foram abordados temas centrais relacionados ao constructo da Autorregulação da Aprendizagem, tais como oferecimento de atividades de apoio, na forma de oficinas, que visam propor reflexões acerca do uso de estratégias de aprendizagem em matemática, a partir das experiências dos estudantes participantes. Nos encontros, abordou-se também alguns temas 
específicos, tais como o estabelecimento de objetivos de aprendizagem, o planejamento de estudos, automonitoramento da aprendizagem, autoavaliação da aprendizagem, a gestão do tempo disponível, a organização e transformação da informação, a atenção e a concentração na tarefa, procrastinação, o ambiente de estudo e procura por ajuda.

A tabela 3 mostra a quantidade de alunos atendidos pelo grupo no período de 2018 até o primeiro semestre de 2020 , nas diversas atividades oferecidas.

\begin{tabular}{|c|c|c|c|c|}
\hline Ano & 2018 & 2019 & $2020 / \mathrm{I}$ & Total \\
\hline Número de alunos atendidos & 1050 & 1258 & 605 & 2.913 \\
\hline
\end{tabular}

Tabela 3: Estudantes apoiados pelo projeto GAMA no período de 2018 a 2020

Ao comparar com a quantidade de estudantes participantes do GAMA no período 20152017 (Tabela 2), é possível perceber que houve um aumento na quantidade de estudantes participantes no período 2018-2020 (Tabela 3). Novamente, credita-se este aumento à diversificação nas atividades do grupo e à maior divulgação das atividades oferecidas utilizando ferramentas tecnológicas, além da mobilidade dos estudantes no ensino virtual em 2020/r.

Salienta-se ainda, a significativa participação dos bolsistas na implementação das atividades do grupo. Como destacam Nachtigall e Pergher (2020), o vínculo que se estabelece entre os alunos ingressantes, os monitores e os professores, nas atividades do GAMA, evidenciam a importância da interação entre pares no processo de aprendizagem e no próprio ato de acolhida destes estudantes pela academia. Nesta perspectiva, Flores (2018) declara que:

\begin{abstract}
A monitoria apresenta o benefício da relação entre estudantes, com uma linguagem próxima, o que facilita a comunicação. Essa benesse pode ser utilizada como um ponto inicial para o traçar de propostas que possibilitem os estudantes a, gradativamente, ampliarem o seu percurso pelos mundos formal axiomático e proceitual simbólico, incorporando-se símbolos econceitos à linguagem. (FLORES, 2018, p. 214)
\end{abstract}

O grupo atende estudantes de mais de trinta cursos de graduação de diferentes unidades acadêmicas da instituição. Embora as atividades do GAMA sejam abertas a toda comunidade acadêmica da UFPel, o público mais assíduo é formado por acadêmicos de nove unidades: Instituto de Física e Matemática (IFM), Centro de Engenharias (CENG), Centro de Desenvolvimento Tecnológico (CDTec), Faculdade de Agronomia (FAEM), Centro de Ciências Químicas, Farmacêuticas e de Alimentos (CCQFA), Instituto de Biologia (IB), Faculdade e Administração e Turismo (FAT), Faculdade de Meteorologia (FMET) e Instituto de Ciências Humanas (ICH). A figura I mostra a quantidade de estudantes que frequentou as atividades do grupo no ano de 2020, separados por unidades acadêmicas. 


\section{Unidades}

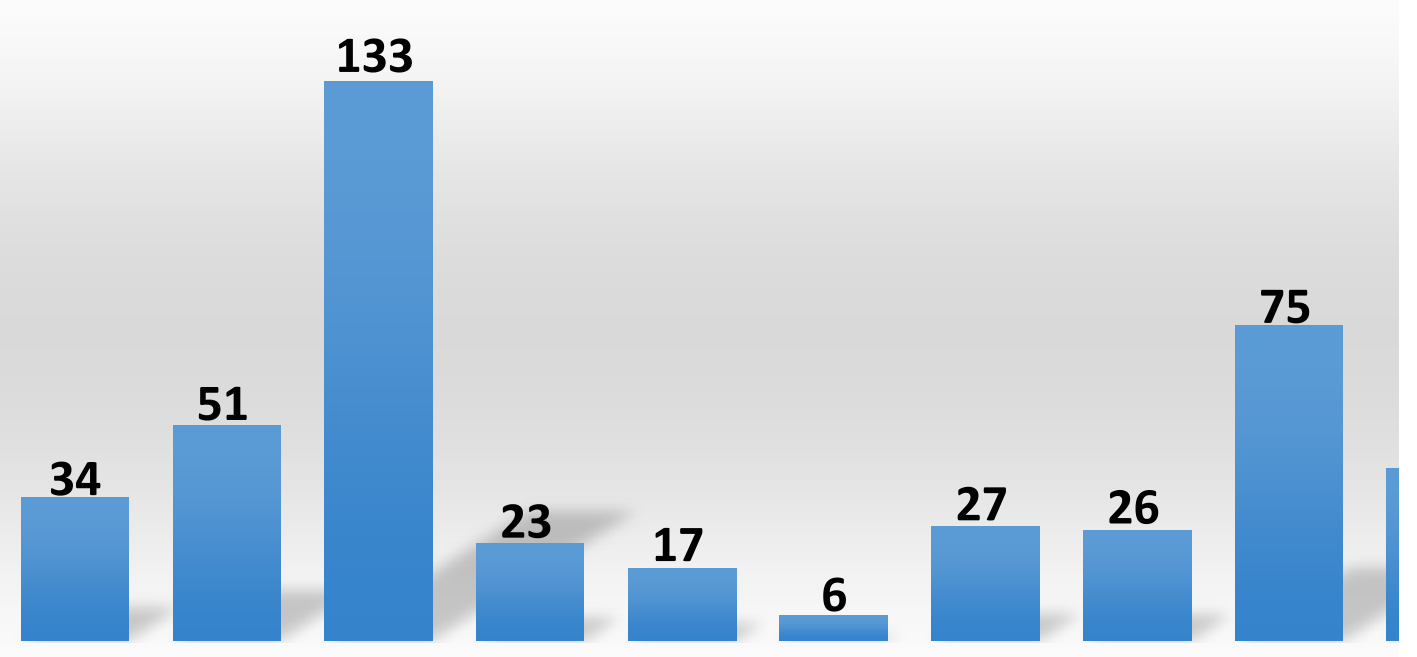

Figura 2: Público participante em 2020, por unidades acadêmicas.

Embora o ano de 2020 tenha sido atípico, a oferta de atividades de forma remota, num momento de distanciamento social, foi salutar para os estudantes, tanto do ponto de vista do reforço de conhecimentos básicos de matemática quanto do ponto de vista do contato social entre alunos, bolsistas e professores. A figura 2 apresenta a quantidade de estudantes que frequentou as atividades do grupo no ano de 2020, separados por cursos de graduação.

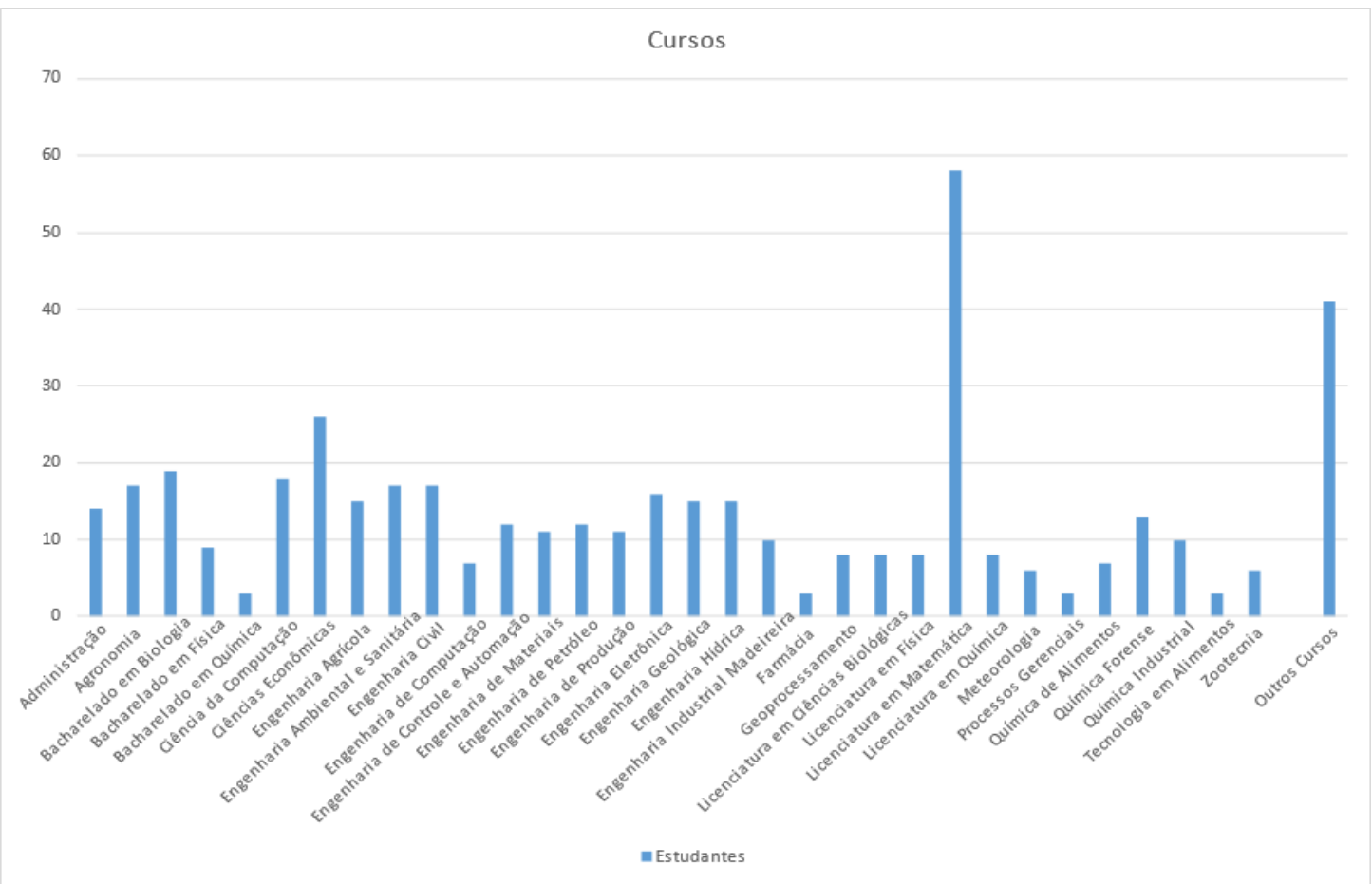

Figura 3: Público participante em 2020, por cursos de graduação da UFPel. 


\section{CONCLUSÕES}

Os resultados nos permitem concluir que, desde a sua criação, o GAMA vem investindo na diversificação das atividades visando alcançar o maior número possível de estudantes. Além das monitorias e do Curso de Matemática Básica, oferecidos pelo GAMA desde a sua criação, em 2010, o grupo implementou as Atividades de Reforço em Cálculo (a partir de 2015), produziu videoaulas (a partir de 2018), oportunizou que alunos e professores da rede pública de ensino participassem das atividades oferecidas, através de atividades de extensão (a partir de 2019), implementou metodologias de ensino inovadoras, tais como a Sala de Aula Invertida (a partir de 2019) e agregou ações que visam abordar questões relacionadas ao aprender a aprender, através das oficinas de Aprendizagem Autorregulada (a partir de 2020).

O GAMA tem se mostrado uma ferramenta importante na colaboração com políticas afirmativas, como o sistema de cotas para ingresso nas Universidades Federais, onde 50\% das vagas devem ser preenchidas por alunos oriundos integralmente do ensino público. O investimento significativo de energia por parte de professores colaboradores, bolsistas, gestores educacionais e demais participantes, consolidam o GAMA como uma das mais relevantes inciativas no combate a evasão e retenção da história da Universidade Federal de Pelotas.

\section{REFERÊNCIAS}

ALMEIDA, Cínthia Soares de. Dificuldades de aprendizagem em matemática e a percepção dos professores em relação a fatores associados ao insucesso nesta área. 2006. $13 \mathrm{f}$. Monografia (Graduação) - Universidade Católica de Brasília, Brasília, 2006.

BACICH, Lilian; MORAN, José. Metodologias ativas para uma educação inovadora: uma abordagem teórico-prático. Porto Alegre: Penso, 2018.

BACICH, Lilian; NETO, Adolfo Tanzi; TREVISANI, Fernando de. (Org.) Ensino Híbrido: Personalização e tecnologia na educação. Porto Alegre: Penso, 2015.

BERGMANN, Jonathan. Aprendizagem invertida para resolver o problema da lição de casa. Porto Alegre: Penso, 2018.

BERGMANN, Jonathan; SAMS, Aaron. Sala de Aula Invertida: Uma metodologia Ativa de Aprendizagem. Rio de Janeiro: LTC, 2018.

BRASIL. Presidência da República. Decreto no 6.096, de 24 de abril de 2007. Institui o Programa de Apoio a Planos de Reestruturação e Expansão das Universidades Federais. Brasília, DF, abr. 2007a.

BRASIL. MEC. REUNI: Reestruturação e Expansão das Universidades Federais: diretrizes gerais. Brasília, ago. 2007b. 
CABRAL, Tânia Cristina Baptista. Metodologias Alternativas e suas Vicissitudes: ensino de matemática para engenharias. Perspectivas da Educação Matemática, Campo Grande, v. 8, n. I7, p. 208-245, 2015.

CABRERA, Luciana Chimendes, et al; Monitorias nos cursos iniciais de cálculo: um olhar sobre os resultados a partir de dados estatísticos. Anais do VI CIEM - Congresso Internacional de Ensino da Matemática, Canoas, 2013.

CERVO, Amado L.; BERVIAN, Pedro A.; SILVA, Roberto da. Metodologia científica. 6. ed. São Paulo: Pearson, 2007.

GIL, Antonio Carlos. Métodos e técnicas de pesquisa social. 6. ed. São Paulo: Atlas, 2018.

FLORES, Jerônimo B. Monitoria de cálculo e processo de aprendizagem: perspectivas à luz da sociointeratividade e da teoria dos três mundos da matemática. 2018. 226f. Tese (Doutorado em Educação em Ciências e Matemática), Pontifícia Universidade Católica do Rio Grande do Sul. Porto Alegre, Porto Alegre, 2018.

HORN, Michel; STAKER, Heather. Blended: usando a inovação disruptiva para aprimorar a educação. Porto Alegre: Penso, 2015.

MATTAR, João. Metodologias Ativas para educação presencial, blended e a distância. São Paulo: Artesanato Educacional, 2017.

NACHTIGALL, Cícero; PERGHER, Rejane. A interação entre pares e a aprendizagem em Cálculo: Experiências no projeto GAMA/UFPel. Brazilian Journal of Development, v. 6, n. 8, p. 62430-62440, 2020 .

NACHTIGALL, Cícero. O uso da Sala de Aula Invertida no ensino superior: preenchendo lacunas em conteúdos de matemática elementar. 2020. 133f. Dissertação (Mestrado em Educação Matemática): Instituto de Física e Matemática. Universidade Federal do Pelotas. Pelotas, 2020.

PANADERO, Ernesto; ALONSO-TÁPIA, Jesus ¿Cómo autorregulan nuestros alumnos? Revisión del modelo cíclico de Zimmerman sobre autorregulación del aprendizaje. Anales de psicología, v. 30, n. 2, p. 450-462, 2014.

ROSÁRIO, Pedro. Diferenças processuais na aprendizagem: avaliação alternativa das estratégias de auto-regulação da aprendizagem. Psicologia, Educação e Cultura, v. V, n. I, p. 87-ı2, 2001.

SAMPIERI, Roberto Hernandez; COLLADO, Carlos Fernandez; LUCIO, Maria Del Pilar Baptista. Metodologia de pesquisa. 5. ed. Porto Alegre: Penso, 2013.

SIMÃO, Ana Margarida da Veiga; FRISON, Lurdes Maria Bragagnolo. Autorregulação da aprendizagem: abordagens teóricas e desafios para as práticas em contextos educativos. Cadernos de Educação, Pelotas, v. 45, n. 2, p. 1-20, maio/agosto 2013.

TALBERT, Robert. Guia para utilização da aprendizagem invertida no ensino superior. Porto Alegre: Penso, 2019.

ZIMMERMAN, Barry J. A social cognitive view of self-regulated academic learning. Journal of Educational Psychology, v. 8I, p. 329-339, 1989.

ZIMMERMAN, Barry J. Attaining self-regulation: a social cognitive perspective, New York., 2000. 